\title{
Weight gain during pregnancy: Does the antenatal care provider make a difference? A retrospective cohort study
}

\author{
Beth Murray-Davis RM PhD, Howard Berger MD, Nir Melamed MD, Haroon Hasan MPH, \\ Karizma Mawjee MA, Maisah Syed MPH, Joel G. Ray MD, Michael Geary MD, Jon Barrett MD, \\ Sarah D. McDonald MD; for the Diabetes, Obesity and Hypertension in Pregnancy Research Network \\ and Southern Ontario Obstetrical Network investigators
}

\section{Abstract}

Background: The primary aim of this study was to examine weight gain during pregnancy and associated adverse outcomes across different types of antenatal health care providers. Our research question examined whether type of antenatal health care provider (family physician, obstetrician, midwife, or family physician plus obstetrician) was associated with differing rates of excess or inadequate weight gain and associated adverse outcomes including being large for gestational age, being small for gestational age, cesarean delivery and preterm birth.

Methods: This retrospective cohort study used data from the Better Outcomes Registry \& Network Information System, 2014-2016, for singleton hospital births at 20-42 weeks' gestation in Ontario. We calculated descriptive statistics to summarize patient characteristics and outcomes by antenatal health care provider. We calculated crude and adjusted relative risks with $95 \%$ confidence intervals (Cls) for the exposure (weight gain during pregnancy) relative to each secondary outcome by health care provider. We calculated population attributable fractions with $95 \%$ Cls to assess the proportion of secondary outcomes that could be prevented if inadequate or excess weight gain (according to the 2009 Institute of Medicine guidelines) were removed by health care provider.

Results: The final cohort consisted of 231697 pregnancies, of which 26043 (11.2\%), 136994 (59.1\%), 32 262 (13.9\%) and 36298 $(15.7 \%)$ were managed by a family physician, obstetrician, midwife, and family physician plus obstetrician, respectively. Rates of weight gain below, within or above recommended levels were 31742 (13.7\%), 71826 (31.0\%) and 128128 (55.3\%), respectively, and did not differ across health care provider groups. No difference was observed in rates of secondary outcomes according to weight gain across health care providers. Excess weight gain was associated with a significant risk of being large for gestational age and cesarean delivery, and inadequate weight gain was associated with an increased risk of being small for gestational age and preterm birth. The population attributable fractions indicated a pronounced contribution of excess weight gain to being large for gestational age across all health care provider groups.

Interpretation: Weight gain during pregnancy and rates of associated secondary outcomes did not differ according to antenatal health care provider. This suggests a need for further research exploring counselling techniques and strategies for all types of antenatal health care providers to use in order to promote optimal weight gain during pregnancy.

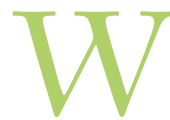
eight gain during pregnancy below or above that recommended substantially increases maternal, fetal and neonatal risks. ${ }^{1-4}$ The 2009 Institute of Medicine guidelines for weight gain during pregnancy recommend that underweight women (body mass index [BMI] $<18.5$ ) gain 13-18 kg during pregnancy, women of normal weight (BMI 18.5-24.9) gain 11-16 kg, overweight women (BMI 25-29.9) gain 7-11 kg, and obese women (BMI $\geq 30$ ) gain 5-9 kg. ${ }^{5}$ Excess weight gain during pregnancy has been associated with an increased risk of gestational diabetes, ${ }^{1}$ gestational hypertension, ${ }^{4}$ augmentation of labour, ${ }^{3,4}$ cesarean delivery, ${ }^{3}$ birth trauma, ${ }^{3}$ neonatal macrosomia and metabolic abnormalities, ${ }^{3,6}$ whereas inadequate weight gain has been linked to fetal growth restriction, low birth weight and prematurity. ${ }^{2}$ Despite the robust literature in this area, recommendations for weight gain for pregnant women are often not met. Only $12 \%$ of Canadian women achieve the recommended weight gain, and over half exceed the recommended

\section{Competing interests: None declared.}

This article has been peer reviewed.

Correspondence to: Beth Murray-Davis, bmurray@mcmaster.ca CMAJ Open 2019. DOI:10.9778/cmajo.20180116 
levels. ${ }^{6,7}$ Cogswell and colleagues ${ }^{8}$ found that pregnant women who received correct advice from their health care provider about weight gain were more likely to achieve appropriate weight gain than those who received incorrect advice or no counselling. Although the majority of health care providers reported counselling women on appropriate weight gain, $30 \%-40 \%$ of women reported that they did not receive counselling, ${ }^{7,9,10}$ and only about a quarter reported being informed about risks associated with inappropriate weight gain. ${ }^{11}$

The standard of care regarding frequency of antenatal appointments for women at low risk in Ontario is consistent across health care providers. ${ }^{12}$ However, the duration of these appointments varies, which may influence the amount of time available for counselling on this topic. McDonald and colleagues ${ }^{12}$ suggested that appointments with obstetricians, which typically last 10 minutes, provided less opportunity to discuss weight gain compared to appointments with family physicians or midwives, which lasted 15 minutes and 30-45 minutes, respectively. Furthermore, there may be differences in the issues and content addressed during counselling owing to philosophical differences in models of care, such as how much emphasis is placed on health teaching and promotion. Studies among antenatal health care providers in Canada and the United States showed that midwives routinely discussed physical activity and food requirements in pregnancy ${ }^{13}$ and that women seen by obstetricians were significantly less likely to receive exercise counselling than those seen by other care providers. ${ }^{14}$ Reported differences between health care providers in the amount of time devoted to the issue of weight gain through counselling and education, and in the content addressed with patients may affect rates of weight gain. There may also be patient-mediated factors that contribute to differences in rates of weight gain during pregnancy between the different provider populations. Since family physicians, midwives and obstetricians all provide primary maternity care to women at low risk in Ontario, patients are able to choose and self-refer to their preferred antenatal health care provider. This may result in a selection bias based on patient beliefs or preferences regarding the approach to care of each profession. For example, women in midwifery care have been shown to be, on average, better educated and more likely to be of middle income and in a stable relationship than those in other provider populations. ${ }^{12}$

The primary aim of this study was to examine weight gain during pregnancy and resulting adverse outcomes across different types of antenatal health care providers. Our research question examined whether type of antenatal health care provider (family physician, obstetrician, midwife, or family physician plus obstetrician) was associated with differing rates of excess or inadequate weight gain and associated adverse outcomes, including being large for gestational age, being small for gestational age, cesarean delivery and preterm birth.

\section{Methods}

\section{Study design and setting}

We conducted a retrospective cohort study to compare the association of weight gain during pregnancy and associated adverse maternal and neonatal outcomes by antenatal health care provider for women who had a singleton hospital birth in Ontario between Apr. 1, 2014, and Mar. 31, 2016. Ontario is the most populous province in Canada, with about 14 million people, which is roughly $40 \%$ of the Canadian population. ${ }^{15}$ Permanent residents of Ontario receive universal health coverage under the government-funded provincial health insurance plan and therefore have equal access to the option of receiving antenatal care from a health care provider of their choice.

\section{Study population}

We identified women using the Better Outcomes Registry \& Network (BORN) Information System (www.bornontario. ca/en/about-born/), a province-wide registry of women and their newborns with a $100 \%$ capture rate. Women included had a singleton hospital birth (live or stillbirth), a plausible body mass index (15-70), a plausible weight gain during pregnancy $(-10 \mathrm{~kg}$ to $50 \mathrm{~kg})$ and an infant of gestational age of 20-42 weeks. The selection of pregnancies for the study cohort is depicted in Figure 1. The BORN Information System contains comprehensive information on maternal and newborn care including data on maternal demographic characteristics, health behaviours and reproductive history,

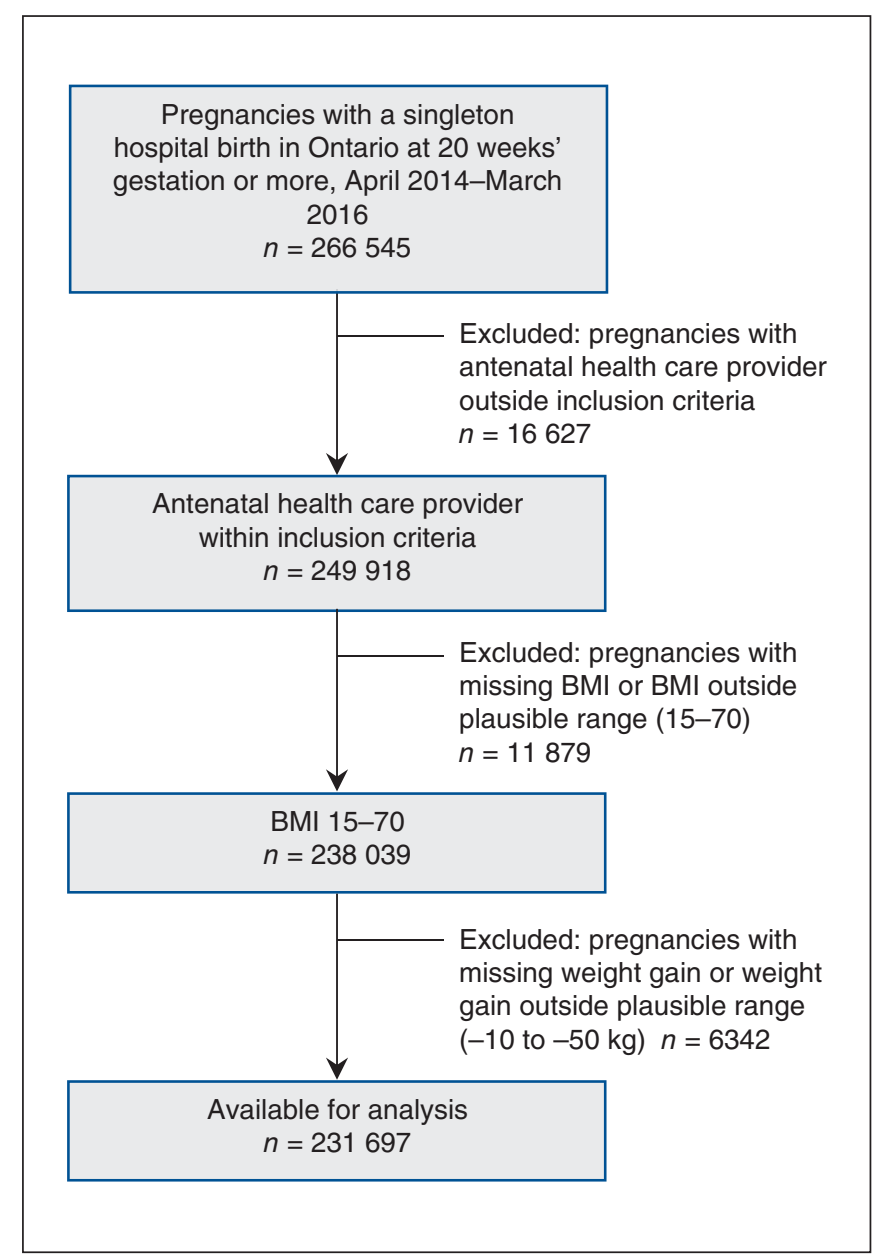

Figure 1: Flow chart showing cohort selection. Note: BMI = body mass index. 
and clinical information related to pregnancy, labour and birth, and fetal and neonatal outcomes. ${ }^{16}$

\section{Exposure and outcomes}

Antenatal health care provider (family physician, obstetrician, midwife, or family physician plus obstetrician) corresponded to the health care provider who provided the majority of antenatal care. The family physician plus obstetrician group comprises women initially seen by a family physician and then transferred to an obstetrician. We removed women with a health care provider corresponding to "other," "unknown" or nurse practitioner from our cohort, as they accounted for a small proportion of the population. If a woman had more than 1 antenatal health care provider, we applied an algorithm that was developed a priori (Supplementary Table S1, Appendix 1, available at www.cmajopen.ca/content/7/2/E283/suppl/DC1).

We defined weight gain during pregnancy as the difference between prepregnancy weight and weight at delivery. Both of these measurements are captured in the BORN database, extracted from the Ontario Perinatal Record at the time of delivery. The standard of care in obstetrics is to record a prepregnancy weight and to assess weight gain at each antenatal visit and record this on the provincial perinatal record. Body mass index is calculated early in pregnancy, and weight gain recommendations are made based on BMI category.

The recommended weight gain in the first trimester is $0.5-2 \mathrm{~kg} .{ }^{5}$ For pregnancies lasting 40 weeks or less, weight gain recommendations for the second and third trimester are specific to prepregnancy BMI categories defined by the World Health Organization guidelines and include a recommended weekly weight gain (Supplementary Table S2, Appendix 1). ${ }^{17}$ We obtained the weekly weight gain in the second and third trimesters by subtracting $2 \mathrm{~kg}$ (the upper limit for the first trimester) from the total weight gain and dividing by the number of weeks in the second and third trimesters (obtained by subtracting the $13 \mathrm{wk}$ of the first trimester from the total number of weeks of the pregnancy). For pregnancies exceeding 40 weeks, we applied the upper limit of weekly recommended weight gain for the second and third trimester up to 40 weeks to the time beyond 40 weeks.

The primary exposure of interest was antenatal health care provider, and the primary outcome was weight gain during pregnancy below, within or above the recommended levels based on the Institute of Medicine guidelines ${ }^{5}$ after adjustment for gestational age as described above. The secondary outcomes were being small for gestational age $(<10$ th percentile), being large for gestational age (>90th percentile), preterm birth (live birth or stillbirth before $37 \mathrm{wk}$ of gestation) and cesarean delivery. We assessed the primary exposure of interest by stratifying the association of weight gain and the secondary outcomes by antenatal health care provider. We used published Canadian reference values to ascertain being small for gestational age and being large for gestational age. ${ }^{18}$

We derived income and postsecondary completion quintiles using Postal Code ${ }^{\mathrm{OM}}$ Conversion File Plus ${ }^{19}$ and the 2011
Canadian census, ${ }^{20}$ respectively. We obtained the remaining patient characteristic and outcome data from the BORN Information System.

\section{Missing data}

The level of missing data in the BORN Information System for prepregnancy BMI and weight at delivery during the study period was $14.0 \%$ and $11.0 \%$, respectively. We took 2 steps to overcome this limitation. First, we identified pregnancies that could be linked to the Prenatal Screening Ontario database, which contains data for about $70 \%$ of pregnancies in Ontario, ${ }^{16}$ to ascertain first-trimester weight. For pregnancies that successfully linked and had first-trimester weight, maternal height and missing prepregnancy weight, we subtracted the upper recommended weight gain during the first trimester $(2 \mathrm{~kg})$ from the first-trimester weight to estimate the prepregnancy weight and subsequently calculate the prepregnancy BMI. ${ }^{5}$ This reduced the level of missing data for prepregnancy BMI from $14.0 \%$ to $10.8 \%$. Second, we assessed the missing at random assumption and determined it to be plausibly met by analyzing the frequency, pattern and reason for missing prepregnancy BMI. We then performed multiple imputation to impute missing prepregnancy BMI and weight at delivery using a chained equation approach among a subset of women with available prepregnancy weight. ${ }^{20} \mathrm{We}$ created 11 imputed data sets, as recommended by Azur and colleagues, ${ }^{21}$ which we then combined across all data sets using Rubin's rule to obtain final model estimates. Following imputation, the level of missing data was reduced from $10.8 \%$ to $4.6 \%$ for prepregnancy BMI and from $11.0 \%$ to $1.4 \%$ for weight at delivery.

\section{Statistical analysis}

We calculated descriptive statistics to summarize patient characteristics and outcomes by antenatal health care provider. We calculated absolute risk differences with $95 \%$ confidence intervals (CIs) to compare the proportion difference for weight gain during pregnancy above, within or below recommended levels by the primary exposure (antenatal health care provider) for all possible combinations. We assigned an absolute risk difference with a standardized difference $\geq 0.10$ to indicate an importance difference. ${ }^{22-25} \mathrm{We}$ did not correct for multiple comparisons.

We ran multivariable Poisson regression models with robust error variance to calculate crude and adjusted relative risks (RRs) with 95\% CIs for weight gain below or above recommended levels relative to within recommended levels, stratified by antenatal health care provider on the secondary outcomes (being small for gestational age, being large for gestational age, preterm birth and cesarean delivery). ${ }^{26}$ Multivariable models to generate adjusted RRs were adjusted for confounders specific to each secondary outcome and were chosen based on clinical expertise and evidence in the literature. ${ }^{27-32}$ Confounders included in the multivariable models for being small for gestational age and being large for gestational age were maternal age, parity, prepregnancy BMI, income quintile, education quintile, smoking, depression, preexisting diabetes, preexisting hypertension and gestational 
Research

\begin{tabular}{|c|c|c|c|c|c|}
\hline \multirow[b]{2}{*}{ Characteristic } & \multicolumn{5}{|c|}{ Antenatal health care provider; no. (\%) of women } \\
\hline & $\begin{array}{c}\text { All } \\
n=231697\end{array}$ & $\begin{array}{c}\text { Family physician } \\
n=26043\end{array}$ & $\begin{array}{l}\text { Obstetrician } \\
n=136994\end{array}$ & $\begin{array}{c}\text { Midwife } \\
n=32362\end{array}$ & $\begin{array}{c}\text { Family physician } \\
\text { + obstetrician } \\
n=36298\end{array}$ \\
\hline \multicolumn{6}{|l|}{ Maternal age, yr } \\
\hline$\leq 24$ & 30896 (13.3) & $5014(19.2)$ & $16215(11.8)$ & $3663(11.3)$ & $6004(16.5)$ \\
\hline $25-29$ & $64476(27.8)$ & $8140(31.3)$ & $35950(26.2)$ & $9487(29.3)$ & $10899(30.0)$ \\
\hline $30-34$ & $84644(36.5)$ & $8713(33.5)$ & $50335(36.7)$ & $12995(40.2)$ & $12601(34.7)$ \\
\hline$\geq 35$ & $51681(22.3)$ & $4176(16.0)$ & 34494 (25.2) & $6217(19.2)$ & $6794(18.7)$ \\
\hline \multicolumn{6}{|l|}{ Prepregnancy body mass index $\dagger$} \\
\hline$<18.5$ (underweight) & $14018(6.0)$ & $1440(5.5)$ & $9086(6.6)$ & $1608(5.0)$ & $1884(5.2)$ \\
\hline $18.5-<25$ (normal weight) & $120434(52.0)$ & $13337(51.2)$ & $70883(51.7)$ & $18401(56.9)$ & $17813(49.1)$ \\
\hline $25-<30$ (overweight) & $55712(24.0)$ & $6485(24.9)$ & $32820(24.0)$ & $7551(23.3)$ & $8856(24.4)$ \\
\hline$\geq 30$ (obese) & $41533(17.9)$ & $4781(18.4)$ & $24205(17.7)$ & $4802(14.8)$ & $7745(21.3)$ \\
\hline \multicolumn{6}{|l|}{ Weight gain during pregnancy } \\
\hline Inadequate & $31804(13.7)$ & $3567(13.7)$ & $19936(14.6)$ & $3742(11.6)$ & $4559(12.6)$ \\
\hline Within recommended levels & 71777 (31.0) & $7768(29.8)$ & $43270(31.6)$ & 10405 (32.2) & $10334(28.5)$ \\
\hline Excess & $128116(55.3)$ & $14708(56.5)$ & 73788 (53.9) & $18215(56.3)$ & 21405 (59.0) \\
\hline Preexisting diabetes & $2149(0.9)$ & $115(0.4)$ & $1544(1.1)$ & $83(0.3)$ & $407(1.1)$ \\
\hline Preexisting hypertension & $1875(0.8)$ & $146(0.6)$ & $1293(0.9)$ & $92(0.3)$ & $344(0.9)$ \\
\hline Gestational diabetes mellitus & $14849(6.4)$ & $1143(4.4)$ & $10245(7.5)$ & $1270(3.9)$ & $2191(6.0)$ \\
\hline Nulliparous & $100347(43.3)$ & $11536(44.3)$ & $57781(42.2)$ & $15359(47.5)$ & $15671(43.2)$ \\
\hline \multicolumn{6}{|l|}{ Gravidity } \\
\hline Primigravid & 74634 (32.2) & $8706(33.4)$ & $42540(31.0)$ & $11708(36.2)$ & $11680(32.2)$ \\
\hline Multigravid & 155619 (67.2) & 17165 (65.9) & 93187 (68.0) & 20652 (63.8) & $24615(67.8)$ \\
\hline Missing & $1444(0.6)$ & $172(0.7)$ & $1267(0.9)$ & $2(<0.1)$ & $3(<0.1)$ \\
\hline \multicolumn{6}{|l|}{ Income quintile } \\
\hline 1 (lowest) & 48414 (20.9) & 5769 (22.2) & 30324 (22.1) & $5560(17.2)$ & $6761(18.6)$ \\
\hline 2 & $46243(20.0)$ & $5041(19.4)$ & $28116(20.5)$ & $6199(19.2)$ & $6887(19.0)$ \\
\hline 3 & 46908 (20.2) & $5255(20.2)$ & 27270 (19.9) & $6594(20.4)$ & $7789(21.5)$ \\
\hline 4 & $48916(21.1)$ & $5227(20.1)$ & $28128(20.5)$ & 7402 (22.9) & 8159 (22.5) \\
\hline 5 (highest) & 37207 (16.1) & $4339(16.7)$ & $20683(15.1)$ & $6063(18.7)$ & $6122(16.9)$ \\
\hline Missing & 4009 (1.7) & $412(1.6)$ & $2473(1.8)$ & $544(1.7)$ & $580(1.6)$ \\
\hline \multicolumn{6}{|l|}{ Education quintile } \\
\hline 1 (lowest) & $45156(19.5)$ & $6479(24.9)$ & $21450(15.7)$ & $6808(21.0)$ & $10419(28.7)$ \\
\hline 2 & 45027 (19.4) & $5675(21.8)$ & 23799 (17.4) & $6651(20.6)$ & 8902 (24.5) \\
\hline 3 & 44908 (19.4) & $4794(18.4)$ & 27549 (20.1) & $6093(18.8)$ & $6472(17.8)$ \\
\hline 4 & 44646 (19.3) & $3756(14.4)$ & 29796 (21.7) & $5857(18.1)$ & $5237(14.4)$ \\
\hline 5 (highest) & $44294(19.1)$ & $3671(14.1)$ & 30088 (22.0) & $6273(19.4)$ & $4262(11.7)$ \\
\hline Missing & 7666 (3.3) & $1668(6.4)$ & $4312(3.1)$ & $680(2.1)$ & $1006(2.8)$ \\
\hline Mental illness & 35271 (15.2) & $4832(18.6)$ & 16291 (11.9) & $6867(21.2)$ & $7281(20.1)$ \\
\hline Depression & $17196(7.4)$ & $2502(9.6)$ & $7591(5.5)$ & 3246 (10.0) & $3857(10.6)$ \\
\hline $\begin{array}{l}\text { Alcohol consumption during } \\
\text { pregnancy }\end{array}$ & $5665(2.4)$ & 899 (3.4) & $2772(2.0)$ & $846(2.6)$ & $1148(3.2)$ \\
\hline
\end{tabular}




\begin{tabular}{|c|c|c|c|c|c|}
\hline \multirow[b]{2}{*}{ Characteristic } & \multicolumn{5}{|c|}{ Antenatal health care provider; no. (\%) of women } \\
\hline & $\begin{array}{c}\text { All } \\
n=231697\end{array}$ & $\begin{array}{c}\text { Family physician } \\
n=26043\end{array}$ & $\begin{array}{l}\text { Obstetrician } \\
n=136994\end{array}$ & $\begin{array}{c}\text { Midwife } \\
n=32362\end{array}$ & $\begin{array}{c}\text { Family physician } \\
\text { + obstetrician } \\
n=36298\end{array}$ \\
\hline \multicolumn{6}{|l|}{ Smoking during pregnancy } \\
\hline Yes & $23342(10.1)$ & $4063(15.6)$ & $12065(8.8)$ & $1880(5.8)$ & $5334(14.7)$ \\
\hline Missing & $9079(3.9)$ & $979(3.8)$ & $7668(5.6)$ & $202(0.6)$ & $230(0.6)$ \\
\hline Drug exposure during pregnancy & $4542(2.0)$ & $954(3.7)$ & $2202(1.6)$ & $407(1.3)$ & $979(2.7)$ \\
\hline \multicolumn{6}{|l|}{ Prenatal classes } \\
\hline Yes & $51293(22.1)$ & $6127(23.5)$ & $26951(19.7)$ & $10120(31.3)$ & 8095 (22.3) \\
\hline Missing & $16810(7.3)$ & $1943(7.5)$ & $10928(8.0)$ & $2460(7.6)$ & $1479(4.1)$ \\
\hline Previous preterm birth & $12256(5.3)$ & $1034(4.0)$ & $8075(5.9)$ & $1305(4.0)$ & $1842(5.1)$ \\
\hline Previous cesarean delivery & $34652(15.0)$ & $2283(8.8)$ & $23543(17.2)$ & $2842(8.8)$ & $5984(16.5)$ \\
\hline Previous abortion & $75100(32.4)$ & $8134(31.2)$ & 45102 (32.9) & $9947(30.7)$ & $11917(32.8)$ \\
\hline Previous term birth & $124036(53.5)$ & $13905(53.4)$ & $74108(54.1)$ & $16352(50.5)$ & $19671(54.2)$ \\
\hline Previous vaginal birth & $96788(41.8)$ & $12132(46.6)$ & $55108(40.2)$ & $14366(44.4)$ & $15182(41.8)$ \\
\hline Previous stillbirth & 3097 (1.3) & $226(0.9)$ & $2241(1.6)$ & $280(0.9)$ & $350(1.0)$ \\
\hline \multicolumn{6}{|l|}{ Nonvertex presentation } \\
\hline Yes & $9190(4.0)$ & $707(2.7)$ & $5536(4.0)$ & $1270(3.9)$ & $1677(4.6)$ \\
\hline Missing & $16179(7.0)$ & $1655(6.4)$ & $13189(9.6)$ & $328(1.0)$ & $1007(2.8)$ \\
\hline Male infant & 118794 (51.3) & $13331(51.2)$ & 70254 (51.3) & $16713(51.6)$ & $18496(51.0)$ \\
\hline
\end{tabular}

diabetes mellitus. Confounders included in the multivariable models for cesarean delivery and preterm birth were maternal age, parity, prepregnancy BMI, income quintile, education quintile, smoking, preexisting diabetes, preexisting hypertension, gestational diabetes, drug exposure, alcohol consumption, mental illness, previous cesarean delivery, previous term birth, previous preterm birth, previous vaginal birth, previous stillbirth, previous abortion, nonvertex presentation and male infant. Gestational age was included as a confounder for cesarean delivery. We used generalized estimating equations in the models to account for multiple pregnancies for a woman within our cohort.

We calculated population attributable fractions and $95 \%$ CIs, based on the adjusted RR, to assess the proportion of the adverse outcome that could be potentially prevented if inadequate or excess weight gain were removed by antenatal health care provider. ${ }^{33} \mathrm{We}$ visualized adjusted RRs and population attributable fractions using forest plots.

All analyses were conducted in SAS version 9.4 (SAS Institute).

\section{Ethics approval}

Ethics approval to conduct this study was obtained from the Hamilton Integrated Research Ethics Board.

\section{Results}

Our final cohort consisted of 231697 pregnancies, of which $26043(11.2 \%)$ were managed by a family physician, 136994 $(59.1 \%)$ by an obstetrician, $32262(13.9 \%)$ by a midwife and $36298(15.7 \%)$ by a family physician plus obstetrician. Maternal characteristics by antenatal health care provider are summarized in Table 1.

\section{Weight gain}

Overall, the rates of total weight gain below, within and above recommended levels were 31742 (13.7\%), 71826 (31.0\%) and 128128 (55.3\%), respectively (Figure 2).

\section{Relative risks of secondary outcomes}

The risks of secondary outcomes were similar between women with inadequate or excess weight gain, stratified by antenatal health care provider (Supplementary Table S3, Appendix 1; Figure 3, Figure 4). Inadequate weight gain was associated with a higher risk of being small for gestational age (adjusted RR 1.38, 95\% CI 1.33 to 1.43 ) and preterm birth (adjusted RR 1.34, 95\% CI 1.27 to 1.41 ) but was protective for being large for gestational age (adjusted RR 0.79, 95\% CI 0.74 to 0.83 ) and was not associated with an increased risk of 


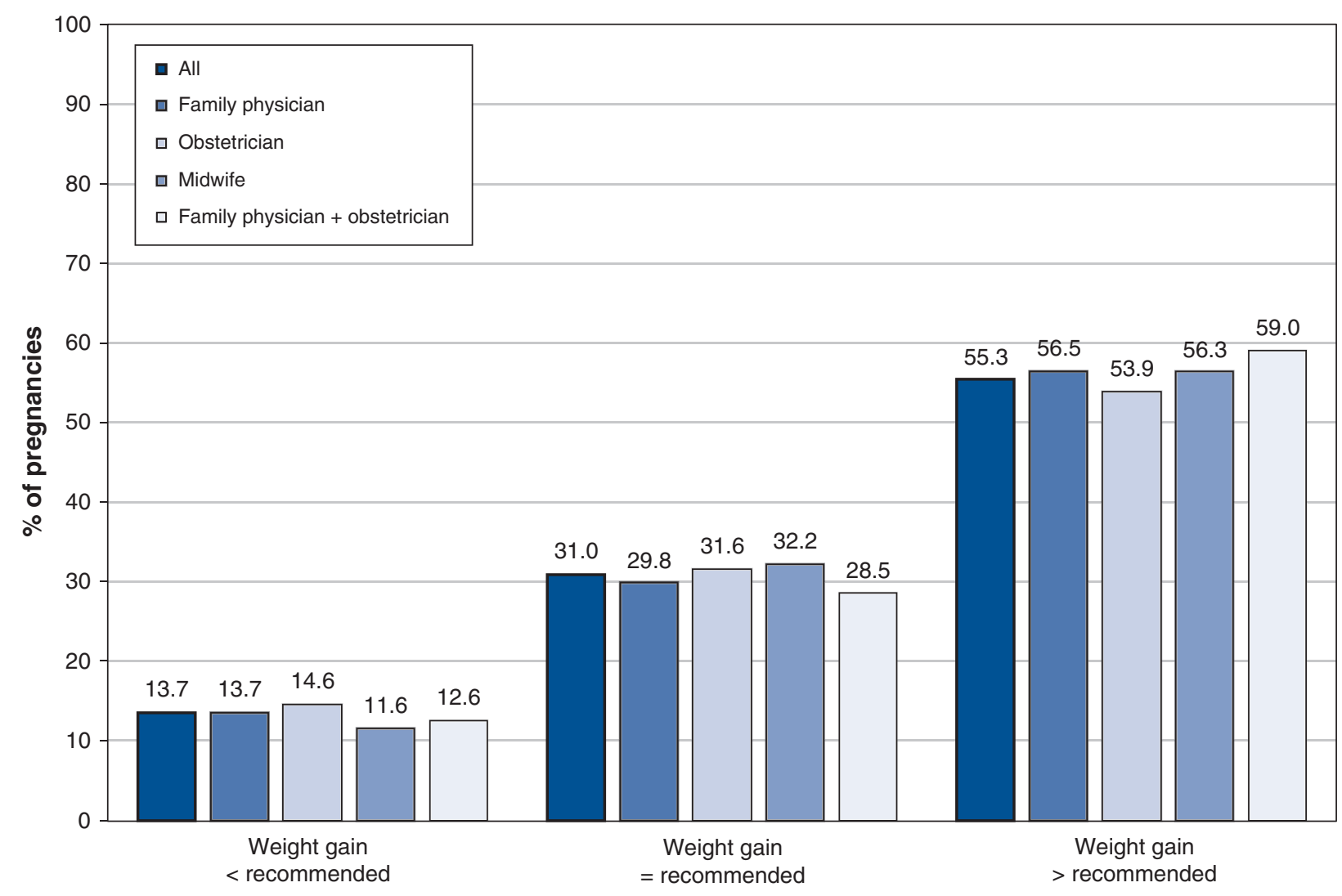

Figure 2: Proportions of pregnancies with weight gain below, within and above recommended levels, by antenatal health care provider.

cesarean delivery (adjusted RR $0.98,95 \%$ CI 0.96 to 1.01 ). Excess weight gain was protective for being small for gestational age (adjusted RR 0.63 , 95\% CI 0.61 to 0.65 ) and was associated with a higher risk of being large for gestational age (adjusted RR 1.88, 95\% CI 1.82 to 1.94 ) and cesarean delivery (adjusted RR 1.10, 95\% CI 1.09 to 1.12); it was not associated with an increased risk of preterm birth (adjusted RR 1.00, $95 \%$ CI 0.96 to 1.04$)$.

\section{Population attributable fractions of secondary outcomes}

No differences were observed in population attributable fractions for all outcomes between antenatal health care providers when women had adequate or inadequate weight gain (Figure 5, Figure 6). Excess weight gain was associated with a negative population attributable fraction $(-23.6 \%, 95 \% \mathrm{CI}$ $-30.0 \%$ to $-17.4 \%$ ) for being small for gestational age but was associated with a population attributable fraction of nearly $35 \%$ for being large for gestational age (population attributable fraction $34.3 \%$, 95\% CI $32.7 \%$ to $35.8 \%$ ). The population attributable fraction for excess weight gain was not significant for preterm birth although it was for cesarean delivery $(5.5 \%, 95 \% \mathrm{CI} 4.1 \%$ to $6.8 \%)$. Inadequate weight gain was associated with a slightly positive population attributable fraction for being small for gestational age $(6.2 \%, 95 \%$ CI $5.2 \%$ to $7.1 \%$ ) and for preterm birth $(4.7 \%, 95 \%$ CI $3.5 \%$ to $5.8 \%$ ) and a slightly protective population attributable fraction for being large for gestational age $(-2.0 \%, 95 \%$ CI $-3.4 \%$ to $0.6 \%)$. The population attributable fraction for inadequate weight gain was not significant for cesarean delivery.

\section{Interpretation}

We did not find a clinically significant association with excess or inadequate weight gain during pregnancy by provider type, despite our hypothesis that different counselling techniques and approaches to care result in differing weight gain during pregnancy. A similar proportion of women gained below, within and above recommended levels across all antenatal care provider groups. Of note, over half of all women, regardless of antenatal health care provider, had excess weight gain.

Absolute risk differences between health care provider groups highlighted 2 findings. First, women in midwifery care may be slightly less likely to gain below recommended levels 


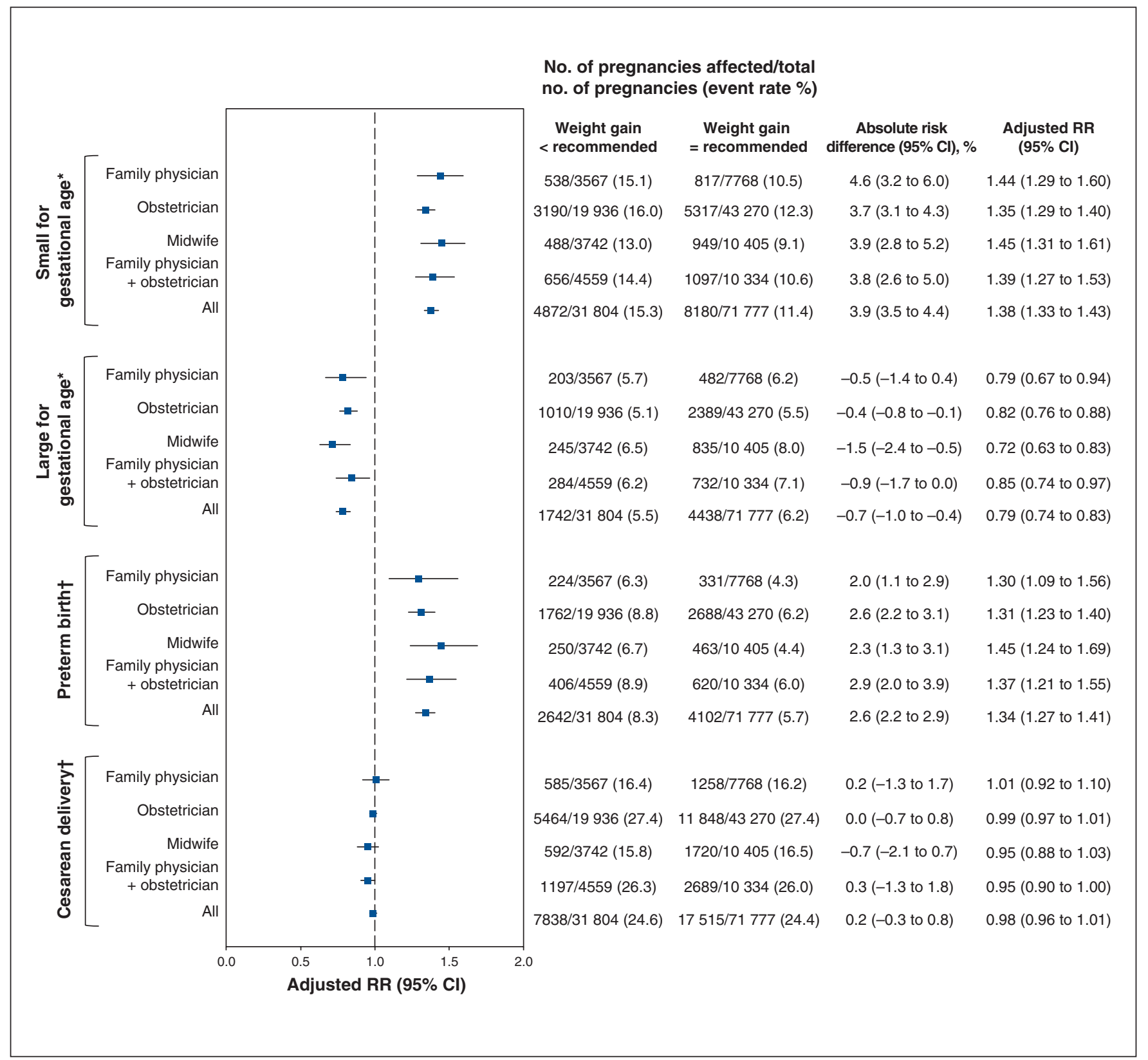

Figure 3: Adjusted relative risk (RR) of being small for gestational age, being large for gestational age, preterm birth and cesarean delivery among pregnancies with a weight below that recommended relative to those with a weight gain within recommended levels, stratified according to antenatal health care provider. Note: $\mathrm{Cl}=$ confidence interval. *Adjusted for maternal age, parity, gestational age at birth, prepregnancy body mass index (BMI), income quintile, education quintile, smoking, depression, preexisting diabetes, preexisting hypertension and gestational diabetes mellitus. †Adjusted for maternal age, parity, gestational age at birth, prepregnancy BMI, income quintile, education quintile, smoking, preexisting diabetes, preexisting hypertension, gestational diabetes, drug exposure, alcohol consumption, mental illness, previous cesarean delivery, previous term birth, previous preterm birth, previous vaginal birth, previous stillbirth, previous abortion, nonvertex presentation and male infant.

than those cared for by an obstetrician. Second, women in the family physician plus obstetrician group were more likely to have excess weight gain than those in the other provider groups. It is possible that the lack of continuous care provider may affect counselling about nutrition and exercise during pregnancy. Consistent and ongoing counselling on these topics may play a role in raising awareness about appropriate weight gain during pregnancy. We found no difference in the rates of the secondary outcomes according to weight gain across health care provider groups. This is an important finding given that women in Ontario can choose which health care provider they see for their pregnancy and the great variation in access to care and care providers throughout the province.

Our research adds to the growing evidence of the magnitude of the association of excess weight gain during 


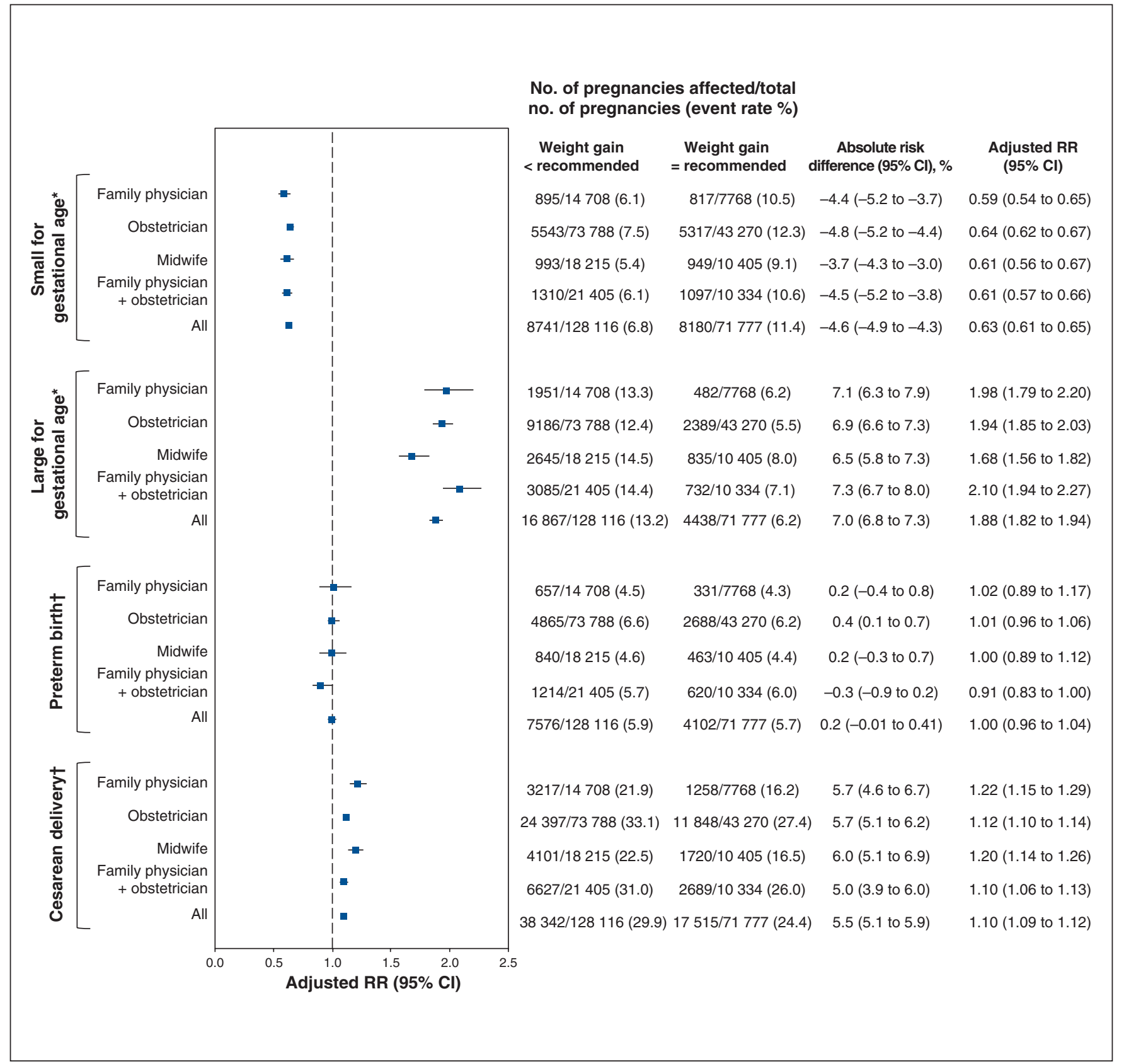

Figure 4: Adjusted relative risk (RR) of being small for gestational age, being large for gestational age, preterm birth and cesarean delivery among pregnancies with a weight gain above that recommended relative to those with a weight gain within recommended levels, stratified according to antenatal health care provider. Note: $\mathrm{Cl}=$ confidence interval. *Adjusted for maternal age, parity, gestational age at birth, prepregnancy body mass index (BMI), income quintile, education quintile, smoking, depression, preexisting diabetes, preexisting hypertension and gestational diabetes mellitus. †Adjusted for maternal age, parity, gestational age at birth, prepregnancy BMI, income quintile, education quintile, smoking, preexisting diabetes, preexisting hypertension, gestational diabetes, drug exposure, alcohol consumption, mental illness, previous cesarean delivery, previous term birth, previous preterm birth, previous vaginal birth, previous stillbirth, previous abortion, nonvertex presentation and male infant.

pregnancy with being large for gestational age and cesarean delivery, and of inadequate weight gain with being small for gestational age and preterm birth. ${ }^{28,34-37}$ As in previous studies, ${ }^{36-40}$ excess weight gain contributed importantly to being large for gestational age (population attributable fraction $34.3 \%$ ), and this was similar across all health care provider groups. This finding shows the critical need for promoting appropriate weight gain during pregnancy to prevent a modifiable risk factor for maternal and neonatal morbidity.

\section{Strengths and limitations}

One strength of our study was its large sample, which enabled adjustment for a number of potential confounders. Our study 


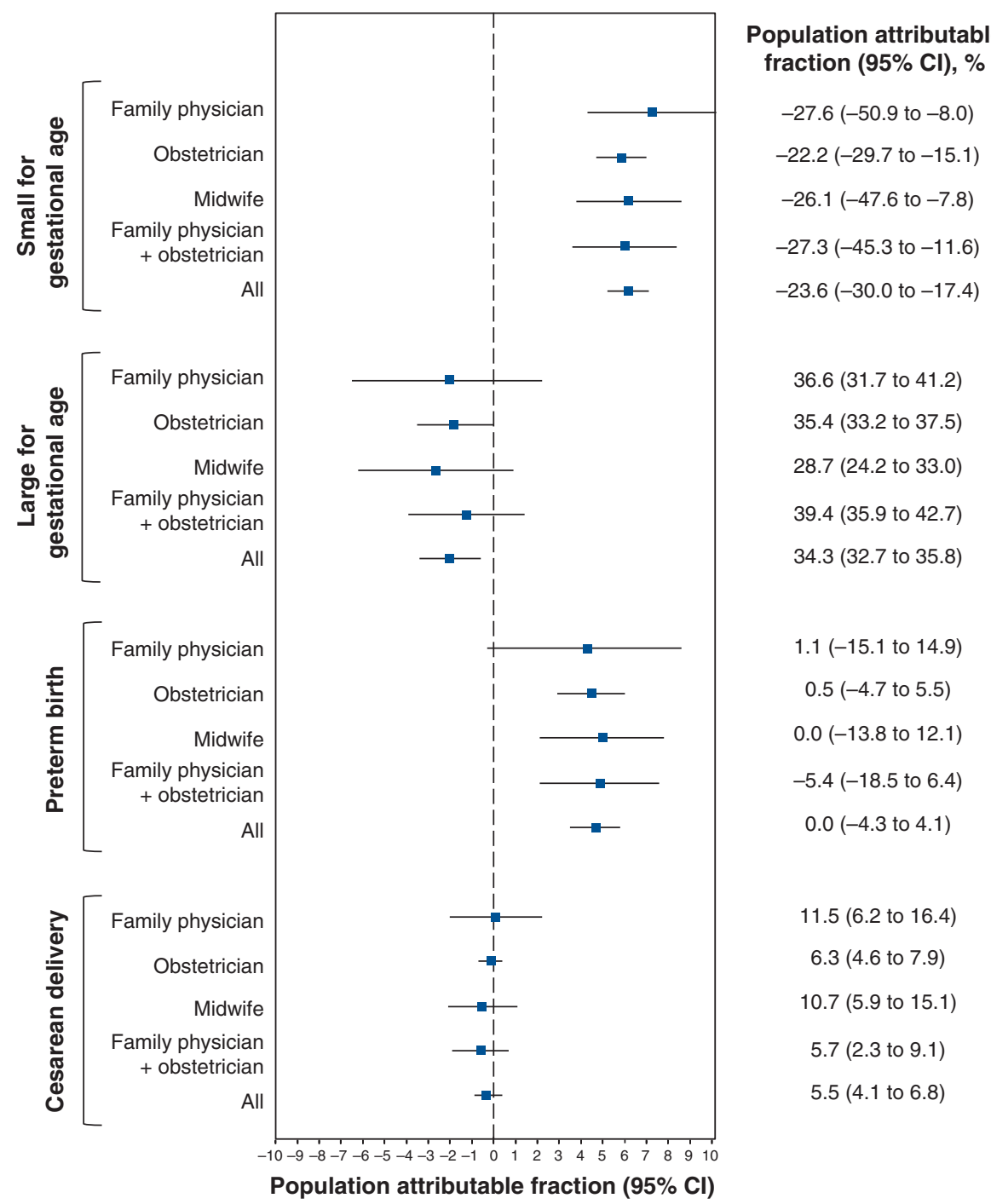

Figure 5: Population attributable fractions of being small for gestational age, being large for gestational age, preterm birth and cesarean delivery for weight gain above that recommended relative to weight gain within recommended levels, stratified according to antenatal health care provider. Note: $\mathrm{Cl}=$ confidence interval, $\mathrm{RR}=$ relative risk.

has limitations. Owing to its retrospective nature, information on several potential confounding variables, such as a history of previously giving birth to an infant who was large for gestational age or small for gestational age, was unavailable. In addition, we lacked data on weight gain per trimester, which may be a key factor for understanding potential time points for intervention.

\section{Conclusion}

We found that weight gain during pregnancy did not differ across antenatal health care provider groups. This suggests a similar need for improvement in counselling to support appropriate weight gain across all care provider types. Also, the rates of adverse outcomes associated with gaining below, within or above recommended levels did not differ according to health care provider. In Ontario, a substantial proportion of babies who are large for gestational age or small for gestational age and of cesarean deliveries could potentially be prevented with appropriate weight gain during the woman's pregnancy. Further research exploring counselling techniques and strategies for promoting optimal weight gain for pregnant women would be beneficial. 


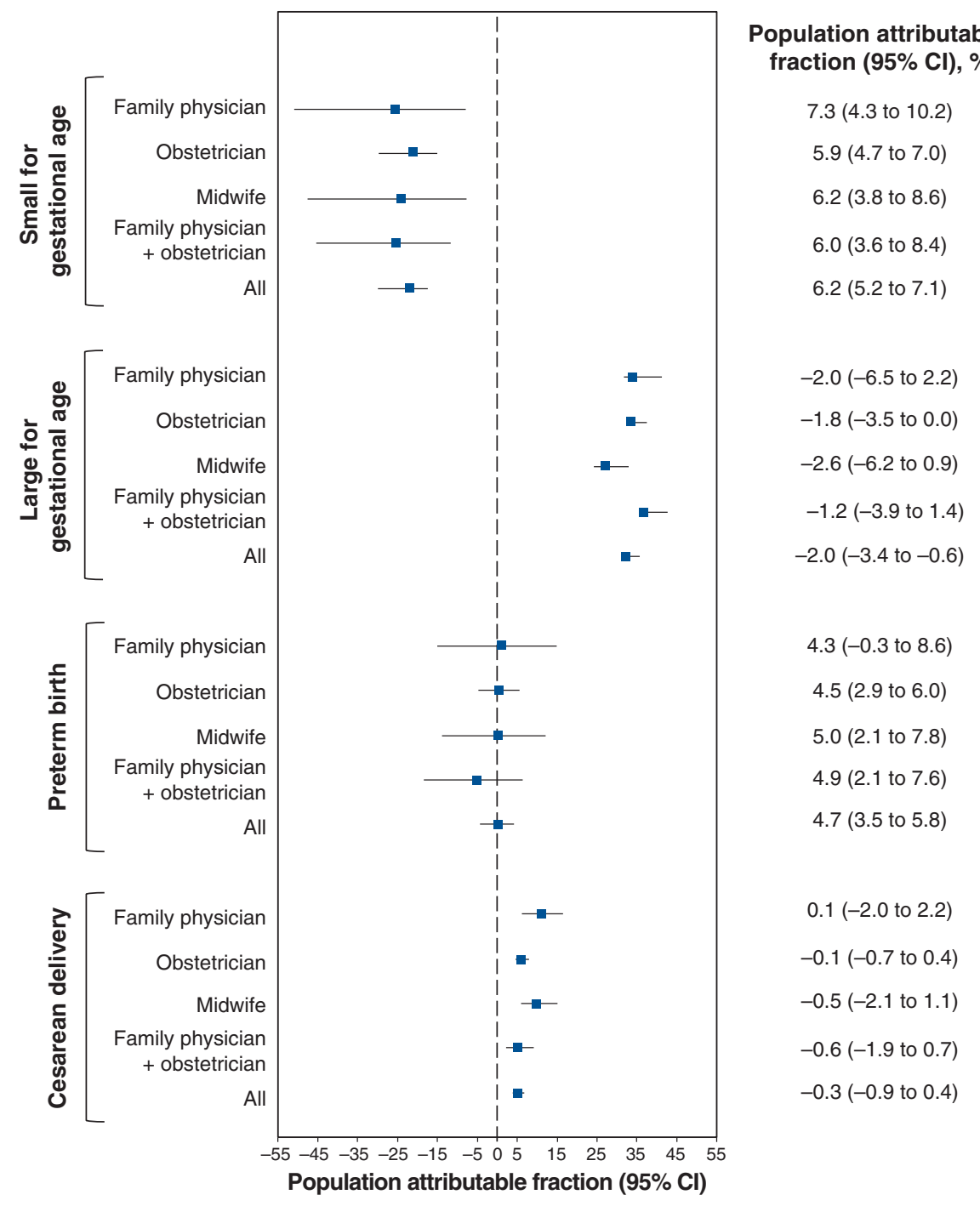

Figure 6: Population attributable fractions of being small for gestational age, being large for gestational age, preterm birth and cesarean delivery for weight gain below that recommended relative to weight gain within recommended levels, stratified according to antenatal health care provider. Note: $\mathrm{Cl}=$ confidence interval, $\mathrm{RR}=$ relative risk.

\section{References}

1. Cedergren M. Effects of gestational weight gain and body mass index on obstetric outcome in Sweden. Int 7 Gynaecol Obstet 2006;93:269-74.

2. Han Z, Lutsiv O, Mulla S, et al.; Knowledge Synthesis Group. Low gestational weight gain and the risk of preterm birth and low birthweight: a systematic review and meta-analyses. Acta Obstet Gynecol Scand 2011;90:935-54.

3. Stotland NE, Hopkins LM, Caughey AB. Gestational weight gain, macrosomia, and risk of cesarean birth in nondiabetic nulliparas. Obstet Gynecol 2004;104:671-7.

4. Thorsdottir I, Torfadottir JE, Birgisdottir BE, et al. Weight gain in women of normal weight before pregnancy: complications in pregnancy or delivery and birth outcome. Obstet Gynecol 2002;99:799-806.

5. Institute of Medicine; National Research Council. Weight gain during pregnancy: reexamining the guidelines. Washington: National Academies Press; 2009.

6. Crane JMG, White J, Murphy P, et al. The effect of gestational weight gain by body mass index on maternal and neonatal outcomes. 7 Obstet Gynaecol Can 2009;31:28-35.
7. McDonald SD, Pullenayegum E, Taylor VH, et al. Despite 2009 guidelines, few women report being counseled correctly about weight gain during pregnancy. Am 7 Obstet Gynecol 2011;205:333.e1-6.

8. Cogswell ME, Scanlon KS, Fein SB, et al. Medically advised, mother's personal target, and actual weight gain during pregnancy. Obstet Gynecol 1999;94:616-22.

9. Ferrari RM, Siega-Riz AM, Evenson KR, et al. A qualitative study of women's perceptions of provider advice about diet and physical activity during pregnancy. Patient Educ Couns 2013;91:372-7.

10. Phelan S, Phipps MG, Abrams B, et al. Practitioner advice and gestational weight gain. 7 Womens Health (Larchmt) 2011;20:585-91.

11. Lutsiv O, Bracken K, Pullenayegum E, et al. Little congruence between health care provider and patient perceptions of counselling on gestational weight gain. 7 Obstet Gynaecol Can 2012;34:518-24.

12. McDonald SD, Pullenayegum E, Bracken K, et al. Comparison of midwifery, family medicine, and obstetric patients' understanding of weight gain during 
pregnancy: a minority of women report correct counselling. 7 Obstet Gynaecol Can 2012;34:129-35.

13. Morris J, Nikolopoulos H, Berry T, et al.; ENRICH team. Healthcare providers' gestational weight gain counselling practises and the influence of knowledge and attitudes: a cross-sectional mixed methods study. BMF Open 2017;7:e018527.

14. Yamamoto A, McCormick MC, Burris HH. US provider-reported diet and physical activity counseling to pregnant and non-pregnant women of childbearing age during preventive care visits. Matern Child Health 7 2014;18: 1610-8.

15. Table 17-10-0005-01: Population estimates on fuly 1st, by age and sex. Ottawa: Statistics Canada; modified 2019 Feb. 25. Available: www150.statcan.gc.ca/t1/ tbl1/en/tv.action? pid=1710000501 (accessed 2018 July 13).

16. Better Outcomes Registry \& Network (BORN) Ontario annual report 2012-2013 and 2013-2014. Ottawa: BORN Ontario; 2015.

17. Global Database on Body Mass Index: an interactive surveillance tool for monitoring nutrition transition. Geneva: World Health Organization; 2006. Available: http://apps.who.int/bmi/index.jsp? introPage=intro.html (accessed 2018 July 13).

18. Kramer MS, Platt RW, Wen SW, et al.; Fetal/Infant Health Study Group of the Canadian Perinatal Surveillance System. A new and improved populationbased Canadian reference for birth weight for gestational age. Pediatrics 2001;108:E35

19. Postal Code ${ }^{\mathrm{OM}}$ Conversion File Plus $(\mathrm{PCCF}+)$ version 6C, reference guide. Cat no 82-F0086-XDB. Ottawa: Statistics Canada; 2015.

20. 2011 National Household Survey: data tables. Cat no 99-014-X2011041. Ottawa: Statistics Canada; modified 2016 Jan. 7.

21. Azur MJ, Stuart EA, Frangakis C, et al. Multiple imputation by chained equations: What is it and how does it work? Int 7 Methods Psychiatr Res 2011;20:40-9.

22. Yang D, Dalton J. A unified approach to measuring the effect size between two groups using SAS®. SAS Global Forum; 2012. Available: http://support.sas. com/resources/papers/proceedings12/335-2012.pdf (accessed 2018 July 13).

23. Hedges LV, Olkin I. Statistical methods for meta-analysis. Phytochemistry 1985;72:369.

24. Cohen J. Statistical power analysis for the behavioral sciences. 2nd ed. Mahwah (NJ): Lawrence Erlbaum Associates; 1988:567.

25. Mamdani M, Sykora K, Li P, et al. Reader's guide to critical appraisal of cohort studies: 2. Assessing potential for confounding. BM7 2005;330:960-2.

26. Zou G. A modified Poisson regression approach to prospective studies with binary data. Am $\mathcal{F}$ Epidemiol 2004;159:702-6.

27. Ehrenberg HM, Mercer BM, Catalano PM. The influence of obesity and diabetes on the prevalence of macrosomia. Am 7 Obstet Gynecol 2004;191:964-8.

28. Hellerstedt WL, Hirnes JH, Story M, et al. The effects of cigarette smoking and gestational weight change on birth outcomes in obese and normal-weight women. Am 7 Public Health 1997;87:591-6.

29. Kramer MS. Determinants of low birth weight: methodological assessment and meta-analysis. Bull World Health Organ 1987;65:663-737.

30. Joseph KS, Kramer MS, Marcoux S, et al. Determinants of preterm birth rates in Canada from 1981 through 1983 and from 1992 through 1994. N Engl 7 Med 1998;339:1434-9.

31. Joseph KS, Young DC, Dodds L, et al. Changes in maternal characteristics and obstetric practice and recent increases in primary cesarean delivery. Obstet Gynecol 2003;102:791-800.

32. Dougherty CR, Jones AD. The determinants of birth weight. Am 7 Obstet Gynecol 1982;144:190-200.

33. Daly LE. Confidence limits made easy: interval estimation using a substitution method. Am 7 Epidemiol 1998;147:783-90.

34. Caulfield LE, Stoltzfus RJ, Witter FR. Implications of the Institute of Medicine weight gain recommendations for preventing adverse pregnancy outcomes in black and white women. Am 7 Public Health 1998;88:1168-74.

35. Margerison Zilko CE, Rehkopf D, Abrams B. Association of maternal gestational weight gain with short- and long-term maternal and child health outcomes. Am f Obstet Gynecol 2010;202:574.e1-8.

36. Dzakpasu S, Fahey J, Kirby RS, et al. Contribution of prepregnancy body mass index and gestational weight gain to adverse neonatal outcomes: population attributable fractions for Canada. BMC Pregnancy Childbirth 2015;15:21.
37. Dzakpasu S, Fahey J, Kirby RS, et al. Contribution of prepregnancy body mass index and gestational weight gain to cesarean birth in Canada. BMC Pregnancy Childbirth 2014;14:106.

38. Oteng-Ntim E, Kopeika J, Seed P, et al. Impact of obesity on pregnancy outcome in different ethnic groups: calculating population attributable fractions. PLoS One 2013;8:e53749.

39. Djelantik AA, Kunst AE, Van Der Wal MF, et al. Contribution of overweight and obesity to the occurrence of adverse pregnancy outcomes in a multiethnic cohort: population attributive fractions for Amsterdam. BfOG 2012; 119:283-90.

40. Lu GC, Rouse DJ, DuBard M, et al. The effect of the increasing prevalence of maternal obesity on perinatal morbidity. Am 7 Obstet Gynecol 2001;185: 845-9.

Affiliations: Midwifery Education Program (Murray-Davis, Syed), Department of Obstetrics and Gynecology, McMaster University, Hamilton, Ont.; Division of Maternal-Fetal Medicine (Berger, Mawjee), Department of Obstetrics and Gynecology, St. Michael's Hospital, University of Toronto; Division of Maternal-Fetal Medicine (Melamed, Barrett), Department of Obstetrics and Gynecology, Sunnybrook Health Sciences Centre, University of Toronto, Toronto, Ont.; Better Outcomes Registry \& Network (BORN) Ontario (Hasan), Children's Hospital of Eastern Ontario, Ottawa, Ont.; Departments of Medicine (Ray) and Obstetrics and Gynaecology (Ray), St. Michael's Hospital, University of Toronto, Toronto, Ont.; Department of Obstetrics \& Gynaecology (Geary), Rotunda Hospital, Dublin, Ireland; Division of Maternal-Fetal Medicine (McDonald), Department of Obstetrics and Gynecology, Department of Radiology (McDonald) and Department of Research Methods, Evidence and Impact (McDonald), McMaster University, Hamilton, Ont.

Contributors: Beth Murray-Davis and Sarah McDonald conceived of the study and drafted the manuscript with support from Haroon Hasan, Karizma Mawjee and Maisah Syed. Beth Murray-Davis, Sarah McDonald, Karizma Mawjee and Haroon Hasan designed the study. Haroon Hasan obtained the data sets from the Better Outcomes Registry \& Network database. Beth Murray-Davis and Haroon Hasan analyzed and interpreted the data with input from all authors. All of the authors critically revised the manuscript for important intellectual content, approved the version to be published and agreed to be accountable for all aspects of the work.

Funding: This study was funded by grant 146442 from the Canadian Institutes of Health Research. Matched funding was provided by the Department of Obstetrics and Gynaecology at the University of Toronto, McMaster University, the Sunnybrook Research Institute, and Providence St. Joseph's and St. Michael's Healthcare. Sarah McDonald is supported by a Tier II Canada Research Chair. Beth Murray-Davis is supported by a Hamilton Health Sciences Early Career Award.

Disclaimer: None of the funding agencies had any role in the idea, design, analyses, interpretation of data, writing of the manuscript or decision to submit the manuscript.

Previous presentation: This study was presented as a poster at the Canadian National Perinatal Research Meeting, Banff, Alta., Feb. 14, 2018.

Supplemental information: For reviewer comments and the original submission of this manuscript, please see www.cmajopen.ca/content/7/2/ E283/suppl/DC1. 